\title{
Stunting and anemia among children 6-23 months old in Damot Sore district, Southern Ethiopia
}

Bereket Geze Malako ${ }^{1 *}$, Benedict Oppong Asamoah², Minyahil Tadesse ${ }^{3}$, Robel Hussen ${ }^{4}$ and Meklit Tesfaye Gebre ${ }^{5}$

\begin{abstract}
Background: Stunting and anemia are long-standing public health challenges which adversely affects the cognitive development and physical wellbeing of children in low income settings. The aim of this study was to assess the prevalence and associated factors of stunting and anemia among 6-23 months old children in Damot Sore District, Southern Ethiopia.

Methods: Cross-sectional survey was conducted among 477 children aged 6-23 months, which were living in Damot Sore District, in April 2017. A multistage sampling technique was used. Villages were randomly selected and systematic random sampling method was used to select study participants. Data on socio-demographic, anthropometric, dietary, blood samples for hemoglobin were collected. Data were entered into EPI Data V. 3.1 and exported into SPSS Version 21.0 for analysis. A principal component analysis (PCA) was done to generate wealth score of households. Binary logistic regression model was used to identify factors associated with the outcome variables (stunting and anemia) separately, those variables having less than a $p$-value of 0.25 were chosen as candidate for multivariable analyses and finally multivariable logistic regression model was used to identify independent variables of each outcomes, with statistical significance set at $p<0.05$ (95\% confidence interval (Cl)).
\end{abstract}

Results: Out of 477 children studied, $31.7 \%$ were stunted and 52\% were anemic. In the multivariable analyses, the number of under five children within a household ( $A O R=4.18,95 \% \mathrm{Cl}: 2.65-6.57)$, drinking water from unsafe source $(A O R=4.08,95 \% \mathrm{Cl}: 1.33-12.54)$ and anemia $(A O R=3.13,95 \% \mathrm{Cl} 2.00-4.92)$ were factors significantly associated with stunting. On the other hand, independent variables of anemia were early initiation of complementary feeding $(\mathrm{AOR}=2.96,95 \% \mathrm{Cl}: 1.23-4.85)$, poor dietary diversity $(\mathrm{AOR}=2.95,95 \% \mathrm{Cl}: 1.78-4.91)$, poor breast feeding practice $(\mathrm{AOR}=2.94,95 \% \mathrm{Cl}: 1.63-5.32)$ and stunting ( $\mathrm{AOR}=3.65,95 \% \mathrm{Cl}: 2.15-6.19)$.

Conclusion: This study revealed higher level of stunting and anemia among children aged 6-23 months than WHO (world health organization) criteria of public health importance. Sustainable promotion of diversified diet, optimal complementary feeding, optimal and complementary breast feeding practices, improving sanitation infrastructure are measures needed to tackle these severe public health challenges.

Keywords: Stunting, Anemia, Southern Ethiopia

\footnotetext{
* Correspondence: berytone@gmail.com

${ }^{1}$ World Vision Ethiopia, Jimma area cluster office, Gewata area development

program, Jimma, Ethiopia

Full list of author information is available at the end of the article
}

(c) The Author(s). 2019 Open Access This article is distributed under the terms of the Creative Commons Attribution 4.0 International License (http://creativecommons.org/licenses/by/4.0/), which permits unrestricted use, distribution, and reproduction in any medium, provided you give appropriate credit to the original author(s) and the source, provide a link to the Creative Commons license, and indicate if changes were made. The Creative Commons Public Domain Dedication waiver (http://creativecommons.org/publicdomain/zero/1.0/) applies to the data made available in this article, unless otherwise stated. 


\section{Background}

Significances of early life experiences to subsequent health outcomes are main public health concerns and increasingly gaining attention in the scientific literature [1]. Early nutritional malignancies such as stunting and anemia have been suggested to cause irreversible health effects of later life courses such as acute and chronic diseases, non-communicable diseases, cognitive development and economic productivity of individuals and the society $[1,2]$.

Anemia $(\mathrm{Hb}<110 \mathrm{~g} / \mathrm{L})$, which could originate from low consumption or absorption of the diet or blood loss and inability to absorb nutrients as a result of infection from intestinal worms is believed to be highly prevalent during infancy. One fourth of the global population is affected by anemia and about $42.6 \%$ of them are children [2]. Various surveys carried out in resource limited settings revealed that the incidence of stunting is at its highest point in children of the age group from 6 to 23 months, because within this period children have a greater demand for macro and micronutrients which are vital for child growth. However, inadequate access to and affordability of quality and sufficient complementary foods, frequent disease episodes, poor sanitation and hygiene practice have been identified as the main causes of malnutrition [2-5].

Anemia might occur at any time and at all stages of the lifespan, but children are the most at risk segment of the population in developing countries, and sub-Saharan Africa bears the highest burden of anemia [3].

Children aged 6 to 23 months have high iron requirements as they are believed to show extremely rapid growth pattern during this period. Trends in Ethiopia indicates that, the magnitude of anemia among 6-23 months old children increased over 10\% between 2011 and 2016 [4, 5].

According to the Ethiopian Demographic Health Survey (EDHS) key indicators report of 2016, 38\% of children below five years of age were stunted nationally, and $38.6 \%$ of under-five children were stunted also in Southern Nations Nationalities and Peoples Region (SNNPR); this shows that there is chronic severity and burden of malnutrition in the country's every corner [5]. A study conducted in Kemba Woreda of Southern Ethiopia also revealed that $18.7 \%$ of children were stunted [6]. Comparisons of two agro-ecological areas in northern and eastern part of Ethiopia indicated that 36.2 and $42.6 \%$ of children aged 6-23 months old were stunted, respectively [7].

Therefore, this study determined the prevalence and predictors of stunting and anemia among children aged 6-23 months old and associated factors in Damot Sore District, Southern Ethiopia.

\section{Methods}

\section{Study area and setting}

Community based cross-sectional survey was carried out among 6-23 months old children residing in 6 villages of Damot Sore District, situated in Southern Nation Nationalities and Peoples Region (SNNPR), which is 326 $\mathrm{km}$ from the capital city of Ethiopia. All children in the aforementioned age group who stayed in the study area during the time of the interview were qualified to take part in the study.

\section{Sample size and sampling procedure}

A formula for estimation of single population proportion was used to calculate the sample size. The following criterions were applied to estimation of the sample size; 95\% confidence level, 5\% error of margin, and $66.6 \%$ prevalence of anemia among children aged 6-23 months old - taken from a previous study in a rural area in northern Ethiopia [8]. The estimated sample size was then adjusted for a non-response rate of $5 \%$ and multiplied by the design effect of 1.5 to obtain a final estimate of 498, the sample size used for this study.

Study participants were selected by a multi - stage sampling technique. From a total of 20 rural villages, 6 were randomly selected using a lottery method.

Sampled number of children per village were proportionally allocated based on their number of households. Finally, using family folder which is found in community health information system (CHIS) of village health posts as a sampling frame, households with children 6-23 months old were selected by simple random sampling method. For a household that have twins or more than one child resident there, one of them was selected by using lottery method. In case of absence of an eligible child in a given household, a substitution was made by a child in the next household. Children with physical deformities of limbs, spine, suffering from diseases and have mental defects were excluded. In addition to this, children who had received blood transfusion and anti helmenthiasis prior (two months) to data collection were excluded.

\section{Data collection}

Data were collected using the questionnaire adopted from previous studies [4, 9] and pre-tested before the start of this study. The questionnaire was first prepared in English language and then translated to Amharic language. Prior to collection of data, the purpose of this study was explained to the study units; their consent to participate was sought and was also informed that their participation in the study was totally voluntary.

The response from the mother/caregiver was recorded after the data collectors read out the questions loud. Date of interview and date of birth was used to calculate age of the child, because the year of birth is inaccurately announced oftentimes. The nutritional status for all children aged 6-23 months old was assessed by taking Anthropometric measurements. 


\section{Data collectors and measurements}

Anthropometric data for this study was collected by six skilled and trained data collectors who administered the questionnaires. Two supervisors closely supervised the process of data collection. Nutritional status was assessed by taking anthropometric body measurements of the children. Length of a child was measured in a recumbent position to the nearest $0.1 \mathrm{~cm}$ by using a portable board provided by UNICEF (United Nations Children's Fund) with an upright movable wooden base. Anthropometric measurements were converted to z-scores of indices using WHO Anthro software [10].

\section{Laboratory investigations}

Hemoglobin count and malaria status of children were investigated. Hemoglobin was measured from capillary blood by aseptically collecting blood sample from the middle finger of study participants, then the analysis have been done by using Automated HemoCue analyser (HEMOCUE Hb 301, HEMOCUE AB, ANGELHOLM SWEDEN) machines and the results were immediately recorded in the field in terms of $\mathrm{g} / \mathrm{dl}$. After adjusting the hemoglobin concentration for changes in the altitude and smoking individual within a household, the results were categorized based on the WHO cut off point, which categorizes a child as anemic if the hemoglobin count is less than $11.0 \mathrm{~g} / \mathrm{dl}$ [11]. Malaria test was done using rapid diagnostic test (RDT) kit, which was commonly used to assess the status of malaria in the community [12]. Blood test for malaria was collected by finger puncture and the result was recorded as positive or negative with regards to species specification.

\section{Data quality control}

Three day training was given for data collectors about study objective, interview techniques, anthropometric measurements and ethical issues during data collection. Rapid diagnostic malaria test results were compared with blood film result by microscope. Standard operating procedures and manufacturer's instructions were strictly followed starting from sample collection up to result reporting for laboratory activities.

The questionnaire was pre-tested on similar setting outside the study area before the collection of actual data. The principal investigator carefully monitored the data collection process.

Quality of the measurements were ensured by maintaining consistency of anthropometric measurement, data collectors were tested using ENA for SMART software before starting data collection.

Standardization: all children were measured without any shoes and clothes were taken off.

Multicollinearity for independent predictors of stunting and anemia were checked and Crombach's alpha was checked for household wealth. Data cleaning were done and outliers were identified and managed properly before the analysis.

\section{Data management}

The data management were done by using three statistical softwares. During the data collection, completeness and uniformity of the data were checked daily before entry.

The data were first entered into EpiData V.3.1 statistical software for coding. Afterwards the data were transported into the software WHO Anthro, where length-for-age Z-scores were computed and further checks done to ensure that flags resulting from wrongly entered data were corrected. After the initial cleaning, all the $\mathrm{z}$-score values which remained as irregular were cleaned from the file and excluded from further analyses. The cleaned file was then exported to SPSS version 21.0 for further analyses.

\section{Statistical analyses}

Bivariate and multivariable logistic regression was used to examine the association between stunting, anemia and the explanatory variables. From the binary regression models, independent variables which were associated with the outcome at $p$-value less than 0.25 were selected as candidate for inclusion in the multivariable logistic regression models. Statistical significance was set at $p<0.05$ and $95 \%$ confidence interval.

\section{Operational definition}

Stunting: is defined as length-for-age Z-scores below minus two $<-2 \mathrm{Z}$ score or Standard deviation of the reference population of World Health Organization (WHO) Multicentre Growth Study. Severe stunting is defined as LAZ scores below minus three $<-3 \mathrm{Z}$ score or Standard deviation of the reference population of WHO Multicentre Growth Study [10].

Anemia: A child is considered to be anemic if the hemoglobin count is less than $11.0 \mathrm{~g} / \mathrm{dl}$ against the WHO reference range [11].

Poor DDS: dietary diversity of less than 4 food categories.

Good DDS: dietary diversity of more than or equal to 4 food categories.

Poor breast feeding practice: failed to breast for at least 8 times per day or inappropriate baby position or switching to the next breast without finishing.

Good breast feeding practice: breast feed for more than or equal to 8 times a day or appropriate baby position or switching to the next breast after finishing one.

\section{Results}

Socio-demographic characteristics of children and mothers From a total of 498 children participated in the study, 477 children were involved in the study yielding a response rate of $95.78 \%$. Twenty-one $21(4.22 \%)$ of sampled 
Table 1 Child and parents related characteristics among children aged 6-23 months in Damot Sore District, Southern Ethiopia, from March to April 2017

\begin{tabular}{|c|c|c|c|}
\hline Characteristics & Categories & Frequency $(N=485)$ & Percent (\%) \\
\hline \multirow[t]{2}{*}{ Sex of the child } & Male & 243 & 50.9 \\
\hline & Female & 234 & 49.1 \\
\hline \multirow[t]{3}{*}{ Age of the mother } & $15-24$ years & 84 & 17.6 \\
\hline & $25-34$ years & 246 & 55.3 \\
\hline & $35-49$ years & 129 & 27.0 \\
\hline \multirow[t]{3}{*}{ Age of the child } & 6-11 months & 190 & 39.8 \\
\hline & 12-17 months & 160 & 33.5 \\
\hline & 18-23 months & 127 & 26.6 \\
\hline \multirow[t]{2}{*}{ Educational status of mother } & No formal education & 307 & 64.4 \\
\hline & Formal education & 170 & 35.6 \\
\hline \multirow[t]{2}{*}{ Educational status of father } & No formal education & 238 & 49.9 \\
\hline & Formal education & 236 & 49.5 \\
\hline \multirow[t]{2}{*}{ Mother's occupation } & Unemployed & 459 & 96.2 \\
\hline & Government/private employee & 18 & 3.8 \\
\hline \multirow[t]{2}{*}{ Father's occupation } & Unemployed & 454 & 95.2 \\
\hline & Government/private employee & 19 & 4 \\
\hline \multirow[t]{2}{*}{ Total number of family size within households } & Less than or equal to 5 & 219 & 45.9 \\
\hline & Greater than 5 & 258 & 54.1 \\
\hline \multirow[t]{2}{*}{ Number of under five children within household } & More than one child & 240 & 50.3 \\
\hline & One child & 237 & 49.7 \\
\hline \multirow[t]{3}{*}{ Wealth } & Low & 201 & 42.1 \\
\hline & Middle & 72 & 15.1 \\
\hline & High & 204 & 42.8 \\
\hline \multirow[t]{2}{*}{ Introduction time of complementary feeding } & Earlier than 6 months & 223 & 46.8 \\
\hline & Just at 6 months & 254 & 53.2 \\
\hline \multirow[t]{3}{*}{ Breast feeding practice } & Poor & 113 & 23.7 \\
\hline & Good & 331 & 69.4 \\
\hline & Never breast feed at all & 33 & 6.9 \\
\hline \multirow[t]{3}{*}{ Source of drinking water } & Piped inside compound & 36 & 7.5 \\
\hline & Public & 351 & 73.6 \\
\hline & Protected well/spring & 90 & 18.9 \\
\hline \multirow[t]{2}{*}{ Toilet } & No facility/bush/field & 12 & 2.5 \\
\hline & Have latrine & 465 & 97.5 \\
\hline \multirow[t]{3}{*}{ Utilization of Insecticide Treated Net (ITN) } & Not appropriately & 45 & 9.4 \\
\hline & Appropriately & 404 & 84.7 \\
\hline & Never had ITN at all & 28 & 5.9 \\
\hline \multirow[t]{2}{*}{ Having diarrhoea } & No & 313 & 65.8 \\
\hline & Yes & 163 & 34.2 \\
\hline \multirow[t]{2}{*}{ Having Malaria } & Yes & 21 & 4.4 \\
\hline & No & 456 & 95.6 \\
\hline \multirow[t]{2}{*}{ Having low dietary diversity score } & Yes & 313 & 65.6 \\
\hline & No & 164 & 34.4 \\
\hline
\end{tabular}


children were dropped from the analysis due to the incompleteness of outcome variables. Mean age of children and mothers were $13.69( \pm 5.41)$ months and $30.11( \pm 5.78)$ years, respectively. As shown in Table 1 among the total households surveyed, 258 (54.1\%) has a total family size greater than five while half of them has more than one under five children. Two hundred and twenty-three (46.8\%) mothers introduce complementary feeding in any other months than just at six months (Table).

\section{Prevalence of stunting among children}

The burden of stunting among the study units was $31.7 \%$ and the mean $( \pm \mathrm{SD})$ stunting (LAZ) of the children was $0.92( \pm 1.31)$. As demonstrated in Fig. 1, Z-score curves were shifted to left of the WHO growth reference curve, which shows stunting, is prevalent in the study area (Fig. 1).

In bivariate analysis as shown in Table 2, age of mothers, age of the children, mothers occupation, number of under five children within household, wealth, source of drinking water, toilet, dietary diversity score and anemia were associated with stunting (Table 2).

\section{Prevalence of anemia}

This study revealed that the magnitude of anemia was found to be $52 \%$ after adjusting for altitude and smoking individual within a household based on WHO $\mathrm{Hb}$ adjusting measurements. In bivariate analysis as shown in Table 3, age of mothers, age of the children, mothers educational status, fathers occupation, number of under five children within household, introduction time of complementary feeding, breast feeding practice of mothers, source of drinking water, toilet, dietary diversity score, growth monitoring and promotion service utilization and stunting were associated with anemia (Table 3).

\section{Independent variables associated with stunting after adjusting for other variables}

Source of drinking water, status of anemia, age of the child, age of the mother, wealth, availability of toilet, number of children under five years of age living in a household, occupation of mother, were found to be statistically significant in bivariate analysis. In a multivariable logistic regression analysis which was as shown on Table 4, the number of under five children within household ( $\mathrm{AOR}=4.18,95 \% \mathrm{CI}: 2.65-6.57)$, drinking water from unsafe source $(A O R=4.08,95 \%$ CI: 1.3312 .54$)$ and anemia $(\mathrm{AOR}=3.13$, 95\% CI 2.004.92) were factors significantly associated with stunting (Table 4).

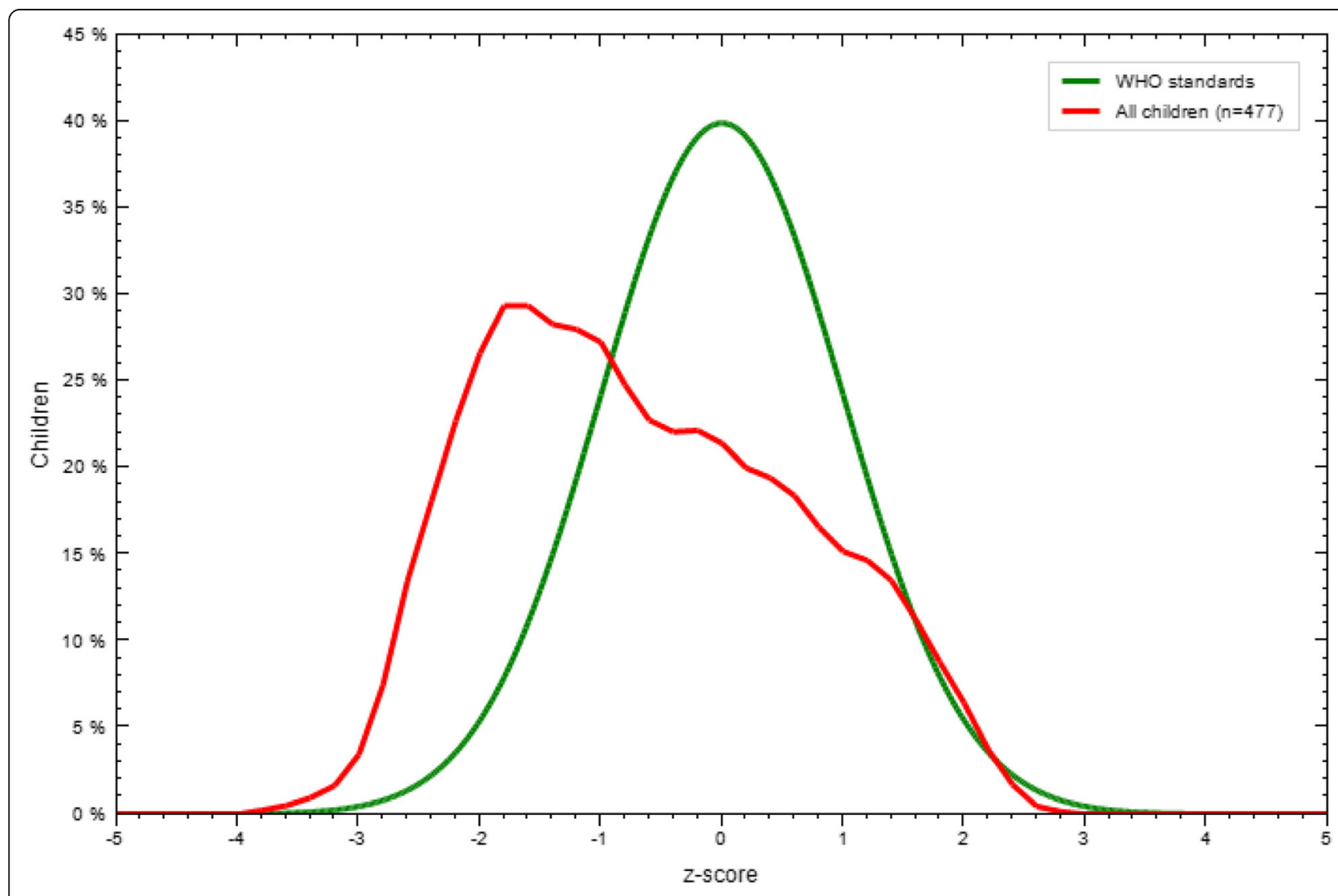

Fig. 1 LAZ-scores compared to WHO growth standards in Damot Sore district, Southern Ethiopia, from March to April 2017 
Table 2 Bivariate analysis that shows independent variables of stunting among children in Damot Sore District, Southern Ethiopia, from March to April 2017

\begin{tabular}{|c|c|c|c|c|c|}
\hline \multirow[b]{3}{*}{ Characteristics } & \multirow[b]{3}{*}{ Categories } & \multicolumn{2}{|c|}{ Stunting status } & \multirow[t]{3}{*}{ COR (95\% C.I.) } & \multirow[t]{3}{*}{$P$} \\
\hline & & Stunted & Not stunted & & \\
\hline & & & & & \\
\hline \multirow[t]{2}{*}{ Sex of the children } & Male & 72 & 171 & $0.83(0.56-1.22)$ & 0.33 \\
\hline & Female & 79 & 155 & 1 & \\
\hline \multirow[t]{3}{*}{ Age of mothers } & $15-24$ years & 35 & 49 & $1.41(0.86-2.33)$ & $0.17^{*}$ \\
\hline & $25-34$ years & 70 & 194 & $1.49(0.89-2.93)$ & $0.13^{*}$ \\
\hline & $35-49$ years & 46 & 83 & 1 & \\
\hline \multirow[t]{3}{*}{ Age of the children } & 6-11 months & 63 & 127 & $1.29(0.73-2.26)$ & 0.38 \\
\hline & 12-17 months & 55 & 105 & $0.65(0.41-1.02)$ & $0.06^{*}$ \\
\hline & $18-23$ months & 33 & 94 & 1 & \\
\hline \multirow[t]{2}{*}{ Educational status of mothers } & No formal education & 94 & 213 & $0.87(0 . .59-1.31)$ & 0.51 \\
\hline & Formal education & 57 & 113 & 1 & \\
\hline \multirow[t]{2}{*}{ Educational status of fathers } & No formal education & 78 & 160 & $1.13(0.77-1.67)$ & 0.53 \\
\hline & Formal education & 71 & 165 & 1 & \\
\hline \multirow[t]{2}{*}{ Mothers occupation } & Unemployed & 149 & 310 & $3.84(0.87-16.94)$ & $0.07^{*}$ \\
\hline & Government/private employee & 2 & 16 & 1 & \\
\hline \multirow[t]{2}{*}{ Fathers occupation } & Unemployed & 145 & 309 & $1.76(0.57-5.39)$ & 0.32 \\
\hline & Government/private employee & 4 & 15 & 1 & \\
\hline \multirow[t]{2}{*}{ Total number of family size within households } & Greater than 5 & 86 & 172 & $1.18(0.80-1.74)$ & 0.39 \\
\hline & Less than or equal to 5 & 65 & 154 & 1 & \\
\hline \multirow[t]{2}{*}{ Number of under five children within household } & More than one child & 111 & 129 & $4.24(2.77-6.477)$ & $0.001^{*}$ \\
\hline & One child & 40 & 197 & 1 & \\
\hline \multirow[t]{3}{*}{ Wealth } & Low & 66 & 135 & $1.23(0.80-1.88)$ & 0.34 \\
\hline & Middle & 27 & 45 & $1.51(086-2.66)$ & $0.15^{*}$ \\
\hline & High & 58 & 146 & 1 & \\
\hline \multirow[t]{2}{*}{ Introduction time of complementary feeding } & Earlier than 6 months & 69 & 154 & $0.94(0.64-1.38)$ & 0.75 \\
\hline & Just at 6 months & 82 & 172 & 1 & \\
\hline \multirow[t]{2}{*}{ Breast feeding practice of mothers } & No & 38 & 75 & $1.14(0.72-1.79)$ & 0.58 \\
\hline & Yes & 102 & 229 & 1 & \\
\hline \multirow[t]{2}{*}{ Source of drinking water } & Public and other sources & 147 & 292 & $4.28(1.49-12.29)$ & $0.04^{*}$ \\
\hline & Piped inside compound & 4 & 34 & 1 & \\
\hline \multirow[t]{2}{*}{ Toilet } & No facility/bush/field & 1 & 11 & $0.19(0.02-1.49)$ & $0.11^{*}$ \\
\hline & Have latrine & 150 & 315 & 1 & \\
\hline \multirow[t]{2}{*}{ Having Diarrhoea } & Yes & 50 & 113 & $1.04(0.57-1.88)$ & 0.89 \\
\hline & No & 23 & 50 & 1 & \\
\hline \multirow[t]{2}{*}{ Having Malaria } & Yes & 7 & 14 & $1.08(0.43-2.74)$ & 0.87 \\
\hline & No & 144 & 312 & 1 & \\
\hline \multirow[t]{2}{*}{ Dietary diversity score } & Poor & 110 & 203 & $1.63(1.06-2.48)$ & $0.02^{*}$ \\
\hline & Good & 41 & 123 & 1 & \\
\hline \multirow[t]{2}{*}{ Growth monitoring and promotion service utilization } & No & 144 & 304 & $1.49(0.62-3.56)$ & 0.37 \\
\hline & Yes & 7 & 22 & 1 & \\
\hline \multirow[t]{2}{*}{ Anemia } & Anemic & 45 & 184 & $3.05(2.02-4.61)$ & $0.001^{*}$ \\
\hline & Not anemic & 106 & 326 & 1 & \\
\hline
\end{tabular}


Table 3 Bivariate analysis that shows independent variables of anemia among children in Damot Sore district, Southern Ethiopia, from March to April 2017

\begin{tabular}{|c|c|c|c|c|c|}
\hline \multirow[t]{2}{*}{ Variables } & \multirow[b]{3}{*}{ Categories } & \multicolumn{2}{|c|}{ Anemia status } & \multirow[t]{3}{*}{ COR (95\% C.I.) } & \multirow[t]{3}{*}{$p$} \\
\hline & & Anemic & Not anemic & & \\
\hline Characteristics & & & & & \\
\hline \multirow[t]{2}{*}{ Sex of the children } & Male & 124 & 119 & $0.92(0.64-1.32)$ & 0.67 \\
\hline & Female & 124 & 110 & 1 & \\
\hline \multirow[t]{3}{*}{ Age of the mother } & $15-24$ years & 44 & 40 & $1.30(0.75-2.26)$ & 0.34 \\
\hline & $25-34$ years & 145 & 119 & $1.44(0.95-2.20)$ & $0.09^{*}$ \\
\hline & $35-49$ years & 59 & 70 & 1 & \\
\hline \multirow[t]{3}{*}{ Age of the child } & 6-11 months & 105 & 85 & $1.72((1.09-2.72)$ & $0.19^{*}$ \\
\hline & 12-17 months & 90 & 70 & $1.79(1.12-2.87)$ & $0.02^{*}$ \\
\hline & 18-23 months & 53 & 74 & 1 & \\
\hline \multirow[t]{2}{*}{ Educational status of mother } & No formal education & 166 & 141 & $1.26(0.87-1.84)$ & $0.22^{*}$ \\
\hline & Formal education & 82 & 88 & 1 & \\
\hline \multirow[t]{2}{*}{ Educational status of father } & No formal education & 126 & 112 & $1.09(0.75-1.56)$ & 0.65 \\
\hline & Formal education & 120 & 116 & 1 & \\
\hline \multirow[t]{2}{*}{ Mother's occupation } & Unemployed & 241 & 218 & $1.74(0.66-4.56)$ & 0.26 \\
\hline & Government/private employee & 7 & 11 & 1 & \\
\hline \multirow[t]{2}{*}{ Father's occupation } & Unemployed & 243 & 211 & $6.14(1.76-21.37)$ & $0.01^{*}$ \\
\hline & Government/private employee & 3 & 16 & 1 & \\
\hline \multirow[t]{2}{*}{ Total number of family size within household } & Greater than 5 & 134 & 124 & $0.99(0.69-1.43)$ & 0.98 \\
\hline & Less than or equal to 5 & 114 & 105 & 1 & \\
\hline \multirow[t]{2}{*}{ Number of under five children within household } & More than one child & 137 & 103 & $1.51(1.05-2.17)$ & $0.03^{*}$ \\
\hline & One child & 111 & 126 & 1 & \\
\hline \multirow[t]{3}{*}{ Wealth } & Low & 103 & 98 & $0.99(0.67-1.46)$ & 0.96 \\
\hline & Middle & 40 & 32 & $1.18(0.68-2.02)$ & 0.55 \\
\hline & High & 105 & 99 & 1 & \\
\hline \multirow[t]{2}{*}{ Introduction time of complementary feeding } & Earlier than 6 months & 142 & 81 & $2.45(1.69-3.54)$ & $0.001^{*}$ \\
\hline & Just at 6 months & 106 & 148 & 1 & \\
\hline \multirow[t]{2}{*}{ Breast feeding practice of mother } & No & 80 & 33 & $2.99(1.89-4.74)$ & $0.001^{*}$ \\
\hline & Yes & 148 & 183 & 1 & \\
\hline \multirow[t]{3}{*}{ Source of drinking water } & Unprotected well & 179 & 172 & $1.84(0.90-3.75)$ & $0.09^{*}$ \\
\hline & Protected well/spring & 56 & 34 & $2.91(1.31-6.50)$ & $0.01^{*}$ \\
\hline & Piped inside compound & 13 & 23 & 1 & \\
\hline \multirow[t]{2}{*}{ Toilet } & No facility/bush/field & 9 & 3 & $2.84(0.76-10.61)$ & $0.12^{*}$ \\
\hline & Have latrine & 239 & 226 & 1 & \\
\hline \multirow[t]{2}{*}{ Utilization of insecticide treated bed net (ITN) } & No & 24 & 21 & $1.08(0.58-1.99)$ & 0.81 \\
\hline & Yes & 208 & 196 & 1 & \\
\hline \multirow[t]{2}{*}{ Having diarrhoea } & Yes & 97 & 66 & $0.97(0.55-1.70)$ & 0.91 \\
\hline & No & 44 & 29 & 1 & \\
\hline \multirow[t]{2}{*}{ Having malaria } & Yes & 10 & 11 & $0.83(0.34-1.99)$ & 0.68 \\
\hline & No & 238 & 218 & 1 & \\
\hline \multirow[t]{2}{*}{ Dietary diversity score } & Poor & 190 & 123 & $2.82(1.90-4.18)$ & $0.001^{*}$ \\
\hline & Good & 58 & 106 & 1 & \\
\hline
\end{tabular}


Table 3 Bivariate analysis that shows independent variables of anemia among children in Damot Sore district, Southern Ethiopia, from March to April 2017 (Continued)

\begin{tabular}{|c|c|c|c|c|c|}
\hline \multirow[t]{2}{*}{ Variables } & \multirow[b]{3}{*}{ Categories } & \multicolumn{2}{|c|}{ Anemia status } & \multirow[t]{3}{*}{ COR (95\% C.I.) } & \multirow[t]{3}{*}{$p$} \\
\hline & & Anemic & Not anemic & & \\
\hline Characteristics & & & & & \\
\hline \multirow[t]{2}{*}{ Growth monitoring and promotion service utilization } & No & 239 & 209 & $2.54(1.13-5.70)$ & $0.02^{*}$ \\
\hline & Yes & 9 & 20 & 1 & \\
\hline \multirow[t]{2}{*}{ Stunting } & Stunted(<-2SD) & 106 & 45 & $3.05(2.02-4.60)$ & $0.001^{*}$ \\
\hline & Not stunted ( $\geq-2 S D)$ & 142 & 184 & 1 & \\
\hline
\end{tabular}

${ }^{*}$ variables with $p<0.25$

\section{Independent variables associated with anemia after adjusting for other variables}

As demonstrated in Table 5, early initiation of complementary feeding ( $\mathrm{AOR}=2.96,95 \% \mathrm{CI}: 1.23-4.85)$, poor dietary diversity $(\mathrm{AOR}=2.95,95 \% \mathrm{CI}: 1.78-4.91)$, poor breast feeding practice (AOR $=2.94,95 \% \mathrm{CI}: 1.63-5.32$ ) and stunting $(\mathrm{AOR}=3.65,95 \% \mathrm{CI}: 2.15-6.19)$ were factors associated with anemia in multivariable logistic regression (Table 5).

\section{Discussion}

This study indicated that out of 477 sampled children aged 6-23 months old, 31.7\% were stunted and 52\% were anemic, which could be described as severe public health challenge according to the WHO criteria [13]. This study investigated that, the magnitude of stunting in our study is nearly same as a study conducted in Shey Bench District, southwest Ethiopia (33.3\%) [14], but much lower than studies conducted in Dabat District (58.1\%) [15] and East Belesa District (57.7\%) [16] north west Ethiopia respectively and Hosanna town, southern Ethiopia (35.4\%) [17] and EDHS-2016 report for SNNPR among children 6-59 months was 38.6\% [5]. However, the result of this study was much higher than a study conducted in Kemba District southern Ethiopia in which $18.7 \%$ children were stunted [6]. This might be due to inappropriate infant and young children feeding practice such as non-diversified diet and inconsistent breast feeding.
Children who drink water from unprotected well have higher risk of being stunted than their counterparts who drink tap water. This is accordant with study conducted in different parts of Ethiopia [18-20]. This might occur as a result of utilization of unimproved drinking water sources and poor sanitation which are directly linked with chronic childhood growth retardation.

This study shows that children living in households having more than one under-five aged children was more stunted as opposed to households with a child less than 5 years of age. This in agreement with a study conducted in Eastern Ethiopia [21], Ethiopian Somali region [22], Mozambique [23], Kenya [24] and Ghana [25]. Under-five children living in households with many siblings of same age category in a low-income setting were subjected to increased competition for resources which results in major child health constraints such as stunting and nutritional deficiencies [26].

According to this study, the prevalence of anemia is higher than the EDHS 2016 report of SNNPR under 5 years of age [27] and much lower than studies conducted in northern (66.6\%) [8] and eastern (53.7\%) [7] parts of Ethiopia, Cameron (66.7\%), Sudan (86\%) and Uganda (58.8\%) [28-30] respectively. This might be attributed to seasonal food shortage since data were collected in spring which is a sunny season characterized by poor consumption of diversified foods and also due to the change made by the existing public health interventions, provision of health information through health extension workers.

Table 4 Multivariable logistic regression analysis of factors which have statically significant association with stunting, in Damot Sore district, Southern Ethiopia, from March to April 2017

\begin{tabular}{|c|c|c|c|c|c|}
\hline \multirow[t]{2}{*}{ Associated factors } & & \multicolumn{2}{|c|}{ Stunting status } & \multirow[t]{2}{*}{ COR (95\% C.I.) } & \multirow[t]{2}{*}{ AOR (95\% C.I.) } \\
\hline & & Stunted & Not stunted & & \\
\hline \multirow[t]{2}{*}{ Number of under five children within household } & More than one child & 111 & 129 & $4.18(2.67-6.57)$ & $4.18(2.65-6.57)^{*}$ \\
\hline & One child & 40 & 197 & 1 & 1 \\
\hline \multirow[t]{2}{*}{ Source of drinking water } & Public and other sources & 147 & 292 & $4.28(1.49-12.29)$ & $4.08(1.33-12.54)$ \\
\hline & Piped inside compound & 4 & 34 & 1 & 1 \\
\hline \multirow[t]{2}{*}{ Anemia } & Anemic & 45 & 184 & $2.9(2.02-4.61)$ & $3.13(2.00-4.92)^{*}$ \\
\hline & Not anemic & 106 & 326 & 1 & 1 \\
\hline
\end{tabular}

${ }^{*} p<0.001{ }^{* *}$ Crude odds ratio with $95 \%$ confidence interval ${ }^{* * *}$ Adjusted odds ratio with $95 \%$ confidence interval 
Table 5 Multivariable logistic regression analysis of factors which have statically significant association with anemia, in Damot Sore district, Southern Ethiopia, 2017

\begin{tabular}{|c|c|c|c|c|c|}
\hline \multirow[t]{2}{*}{ Associated factors } & & \multicolumn{2}{|c|}{ Anemia status } & \multirow{2}{*}{$\begin{array}{l}\text { COR** } \\
(95 \% \text { C.I.) }\end{array}$} & \multirow{2}{*}{$\begin{array}{l}\text { AOR*** } \\
(95 \% \text { C.I.) }\end{array}$} \\
\hline & & Anemic & Not anemic & & \\
\hline \multirow[t]{2}{*}{ Dietary diversity score } & low & 190 & 123 & $2.82(1.90-4.18)^{*}$ & $2.95(1.78-4.91)^{*}$ \\
\hline & high & 58 & 106 & 1 & \\
\hline \multirow{2}{*}{$\begin{array}{l}\text { Introduction time } \\
\text { of complementary } \\
\text { feeding }\end{array}$} & Earlier than 6 months of age & 142 & 81 & $2.45(1.69-3.54)$ & $2.96(4.85)$ \\
\hline & Just at 6 months of age & 106 & 148 & 1 & \\
\hline \multirow[t]{2}{*}{ Breast feeding } & No & 80 & 33 & $2.99(1.89-4.74)$ & $2.94(1.63-5.32)$ \\
\hline & Yes & 148 & 183 & 1 & \\
\hline \multirow[t]{2}{*}{ LAZ } & $<2 S D$ & 106 & 45 & $3.05(2.02-4.60)$ & $3.65(2.15-6.19)$ \\
\hline & Normal & 142 & 184 & 1 & \\
\hline
\end{tabular}

${ }^{*} p<0.001{ }^{* *}$ Crude odds ratio with $95 \%$ confidence interval ${ }^{* * *}$ Adjusted odds ratio with $95 \%$ confidence interval

Children exposed to lower dietary diversity were 2.95 times more anemic as compared to their counterparts exposed to a higher dietary diversity. This is in line with a study conducted in Wag-Himra, northern Ethiopia, in which poor micronutrient bioavailability related with anemia was observed [31]. This could be due to seasonal unavailability of citric fruits which enhances iron absorption and the socio-economic barriers to provide animal source foods such as meat.

The finding of this study observed that, children who started complementary feeding earlier than 6 months were 2.96 times more likely to develop anemia than children who start at 6 months. On the contrary, a study conducted in Nepal [32] and a systematic review [33] revealed that early introduction of complementary foods had improved hemoglobin concentrations of children. This study is consistent with a study conducted in northern Ethiopia [8], Lebanon [34], Brazil [35] and China [36]. Which reports that early introduction of solid or liquid foods is related with childhood anemia. Early exposure of infants before 6 months of age increases the risks of infections and mal-absorption. This might be due to lack of knowledge about adequacy of excusive breast feeding alone to infants; and thus, they introduce at least cow milk earlier than 6 months.

Government of Ethiopia engaged in many actions to tackle nutritional problems, among them social protections, national nutrition program, community based nutrition, micronutrient supplementations, Seqota declarations and other strategies were used but the problems are still at their climax $[4,5]$.

Ghana has a history of implementing integrated anemia control programs and reduced prevalence of anemia though multi-sectoral collaboration, home fortification of foods with multiple micronutrient powders for children 6-23 months, simultaneously with malaria prevention [37]. Similarly, to reduce stunting 'Seqota' Declaration is a special commitment of government of Ethiopia which will be achieved under the NNP, will be implemented by multi-sectors and on a progress [38]. Implementation of this study is, to update the level of stunting and anemia in this area which will help respecting government offices (Ministry of health, agriculture, education, etc.), as an input for stimulating its efforts to achieve its plan of improving the productivity of individuals and national GDP.

It will also uses as an input to for Growth and Transformation Plan GTP-2 (2016-2020), which were targeted to reduce nutritional problems, through the way it will contribute to the achievement of sustainable development goals.

\section{Anemia and stunting linkage}

This study suggested that childhood growth retardation strongly correlates with anemia in children less than 5 years of age.

This relationship could be ascribed significantly to anemia and stunting as one of the major outcomes of chronic nutritional deficiencies and hemoglobin concentration is used for measurement of child growth and long term deficiency led synergic effect $[1,7]$.

\section{Limitation of the study}

We encounter a number of limitations: because it is a cross-sectional study, casual inference cannot be made and also it did not show which preceded, whether outcomes or associated factors. Parasite investigation was not done.

\section{Conclusion}

This study revealed higher level of stunting and anemia among children aged 6-23 months than WHO (world health organization) criteria of public health importance. Sustainable promotion of diversified diet, optimal complementary feeding, optimal and complementary breast feeding practices, improving sanitation infrastructure are measures needed to tackle these severe public health 
challenges. Households with more than one under-five children and unsafe source of drinking water and anemia were factors significantly associated with stunting. On the other hand, early initiation of complementary feeding, poor dietary diversity, poor breast feeding practice and stunting were significantly associated with anemia.

Behavioral change communication on sustainable promotion of diversified diet, optimal and complementary breast feeding practices and sanitation infrastructure are measures needed to tackle these severe public health challenges. Strengthening integration of nutrition intervention activities between and within the existing health facilities and the community on maternal, newborn and child health services. Multiple micronutrient powders (sprinkles) should be initiated by partners and longitudinal studies need to be conducted to identify specific etiologies and root causes of stunting and anemia.

\section{Abbreviations \\ ANC: Antenatal Care; AOR: Adjusted Odds Ratio; CBC: Complete Blood Count: CHIS: Community Health Information System; Cl: Confidence Interval; COR: Crude Odds Ratio; DDS: Dietary Diversity Score; EDHS: Ethiopian Demographic Survey; FFQ: Food Frequency Questionnaire; GDP: Gross domestic production; GPS: Global Positioning System; GTP: Growth and transformation plan; Hb: Hemoglobin; ITN: Insecticide Treated Bed Net; LAZ: Length-for-Age; OR: Odds Ratio; PCA: Principal Component Analysis; RDT: Rapid Diagnostic Test; SNNPR: Southern Nations Nationalities and Peoples Regional State; UNICEF: United Nations Children's Fund; WHO: World} Health Organization

\section{Acknowledgements}

Damot Sore district health office, the supervisors, data collectors, study participants, Jimma University.

\section{Funding}

Not applicable.

\section{Availability of data and materials}

The corresponding author avails the data and other related material upon important demand.

\section{Authors' contributions}

BGM: Conception of the research idea, study design, coordination of data collection, data entry, statistical analysis, interpretation and drafted the manuscript; MT, BOA, RH, and MTG: analyzed data, interpreted and reviewed the drafted manuscript. All authors read and approved the final version of the manuscript.

\section{Ethics approval and consent to participate}

Ethical clearance was obtained from Ethical Review Board of Jimma University, School of Public Health. Informed written consent was obtained from mothers of sampled children prior to data collection, and additional briefing was made regarding the aim of the study. Informed verbal consent was taken for study subjects who do not have formal education, in addition to that, appropriate written consent was obtained from parents, in the case of minor's participation. Secrets of the information offered were ensured and respondents' was privacy maintained. At the time of collection of the data, each study units was informed that their involvement was non-mandatory, and that they can avoid the interview at any given time during the commencement of the study.

\section{Consent for publication}

Not applicable.

\section{Competing interests}

This study is free of any competing financial and non-financial interests as per author's declaration.

\section{Publisher's Note}

Springer Nature remains neutral with regard to jurisdictional claims in published maps and institutional affiliations.

\section{Author details}

${ }^{1}$ World Vision Ethiopia, Jimma area cluster office, Gewata area development program, Jimma, Ethiopia. ${ }^{2}$ Social Medicine and Global Health, Department of Clinical Sciences, Malmo, Lund University, Lund, Sweden. ${ }^{3}$ Health Sciences and Medicine College, Wolaita Sodo University, Wolaita Sodo, Ethiopia. ${ }^{4}$ School of public health, Dilla University, Dilla, Ethiopia. ${ }^{5}$ School of Public Health and Medical Sciences, Jimma University, Jimma, Ethiopia.

Received: 4 August 2018 Accepted: 20 December 2018

Published online: 07 January 2019

\section{References}

1. Burke RM, Leon JS, Suchdev PS. Identification, Prevention and Treatment of Iron Deficiency during the First 1000 Days. 2014:4093-114.

2. Black RE, Victora CG, Walker SP, Bhutta ZA, Christian P, de Onis M, et al. Maternal and Child Nutrition 1 Maternal and child undernutrition and overweight in low-income and middle-income countries. Lancet. 2013; 382(9890):427-51.

3. THE GLOBAL PREVALENCE OF ANAEMIA IN 2011. 2011.

4. Agency CS, Ababa A. Ethiopia Demographic and Health Survey. 2012; (March)

5. Agency, Central Statistical Addis Ababa, Ethiopia and the DHS program ICF Rockville, Maryland U. EDHS 2016 Key indicators report Addis Ababa; 2016. p. 1-59.

6. Agedew $E_{1}$ Chane T. Prevalence of Stunting among Children Aged 6-23 Months in Kemba Woreda, Southern Ethiopia : A Community Based CrossSectional Study. 2015;2015.

7. Roba KT, O'Connor TP, Belachew T, O'Brien NM. Anemia and undernutrition among children aged 6-23 months in two agro ecological zones of rural Ethiopia. Pediatr Health Med Therap. 2016;7:131-40.

8. Woldie H, Kebede Y, Tariku A. Factors associated with Anemia among children aged $6-23$ months attending growth monitoring at Tsitsika health center, vol. 2015. wag-Himra zone, Northeast Ethiopia: Hindawi Publishing Corporation; 2015.

9. Ruzita AT, Poh BK. Development and validation of a food frequency questionnaire for dietary intake assessment among multi-ethnic primary school-aged children. Singapore Med J. 2015;56(12):687-94.

10. Multicentre WHO, Reference G, Group S WHO Child Growth Standards based on length/height, weight and age 2006;76-85.

11. Haemoglobin concentrations for the diagnosis of anaemia and assessment of severity. : 1-6.

12. October P. MALARIA DIAGNOSIS : A GUIDE FOR SELECTING ( RDT ) KITS - 1 edition. 2007;(October):1-7.

13. WHO/UNICEF/UNU. Iron deficiency anaemia: assessment, prevention, and control, vol. 2001. Geneva: World Health Organization; 2001. (WHO/NHD/01. 3); 2001. Available from: http://www.wvi.org/nutrition/article/anaemiaassessment-guidance

14. Teferi MB, Hassen HY, Kebede A, Adugnaw E. Prevalence of Stunting and Associated Factors among Children Aged 06-59 Months In Southwest Ethiopia : A Cross-Sectional Study. Journal of Nutritional Health and Food Science. 2016:2016:1-6.

15. Derso T, Tariku A, Biks GA, Wassie MM. Stunting, wasting and associated factors among children aged 6 - 24 months in Dabat health and demographic surveillance system site : a community based cross- sectional study in Ethiopia. BMC Pediatr. 2017:1-9.

16. Fentahun $\mathrm{W}$, Wubshet $\mathrm{M}$, Tariku A. Undernutrition and associated factors among children aged 6-59 months in east Belesa District, Northwest Ethiopia : a community based cross-sectional study. BMC public health [internet]. BMC Public Health. 2016:1-10 Available from: https://doi.org/10. 1186/s12889-016-3180-0.

17. Moges B, Feleke A, Meseret S, Doyore F. Magnitude of Stunting and Associated Factors Among 6-59 Months Old Children in Hossana Town Southern Ethiopia. J Clin Res Bioeth. 2015;6(1):1-8. 
18. Determinants of stunting among children aged 6-59 months at Kindo Didaye woreda, Wolaita Zone, Southern Ethiopia: Unmatched case control study. 2017;189106.

19. Dearden KA, Schott W, Crookston BT, Humphries DL, Penny ME. Children with access to improved sanitation but not improved water are at lower risk of stunting compared to children without access : a cohort study in Ethiopia ,. BMC public health [internet]. BMC Public Health. 2017:1-19 Available from: https://doi.org/10.1186/s12889-017-4033-1.

20. Cumming O, Cairncross S. Review Article Can water, sanitation and hygiene help eliminate stunting ? Current evidence and policy implications. Matern Child Nutr. 2016;12:91-105.

21. Yisak H, Gobena T, Mesfin F. Prevalence and risk factors for under nutrition among children under five at Haramaya district, eastern Ethiopia. BMC Pediatr [internet]. BMC Pediatr. 2015:1-7 Available from: https://doi.org/10. 1186/s12887-015-0535-0.

22. Ma A, Birhanu D, Melaku S, Tolossa D, Mohammed Y, Gebremicheal K. Magnitude and factors associated with malnutrition in children $6-59$ months of age in Shinille Woreda, Ethiopian Somali regional state : a crosssectional study. BMC Nutr [internet]. BMC Nutrition. 2016:1-12. Available from: https://doi.org/10.1186/s40795-016-0079-1.

23. Cruz LMG, Azpeitia GG, Súarez DR, Rodríguez AS, Ferrer JFL, Serra-Majem L. Factors Associated with Stunting among Children Aged 0 to 59 Months from the Central Region of Mozambique. Nutrients. 2017;9(5):491.

24. Masibo PK. Trends and Determinants of Malnutrition among Children Age 0-59 Months in Kenya (KDHS 1993, 1998, 2003 and 2008-09) [WP89]. 2013; (February).

25. Kofuor E, Darteh M, Acquah E, Kumi-kyereme A. Correlates of stunting among children in Ghana. 2014;14(1):1-7.

26. Rana MJ, Goli S. The Returns of Family Planning: Macro-level Assessment of Effect of Contraceptive Use on Women Anemia and Childhood Undernutrition. J Biosoc Sci (Cambridge University Press). https://doi.org/10. 1017/S0021932016000717.

27. Ababa A. The Federal Democratic Republic of Ethiopia Ministry of Agriculture and natural resource nutrition sensitive agriculture draft strategic plan MoANR. Ethiopia; 2016.

28. Modestine M, Sop K, Mananga M. Risk factors of anemia among young children in rural Cameroon. Int J Curr Microbiol App Sci. 2015;4(3):925-35.

29. Mahmoud HH, Muddathir AM, Osman SEM, Alkhawad MA, Awadia K. Iron Deficiency Anemia among Children under Three years in. 1985;400.

30. Kuziga F, Adoke Y, Wanyenze RK. Prevalence and factors associated with anaemia among children aged 6 to 59 months in Namutumba district, Uganda : a cross-sectional study. BMC Pediatr [internet]. BMC Pediatr. 2017: 1-9. Available from: https://doi.org/10.1186/s12887-017-0782-3.

31. Michaelsen KF, Hoppe C, Roos N, Kaestel P, Stougaard M, Mølgaard C, et al. Choice of foods and ingredients for moderately malnourished children 6 months to 5 years of age. Food Nutr Bull. 2009;30(3):S343-404.

32. Chandyo RK, Henjum S, Ulak M, Lyman ALT, Ulvik RJ, Shrestha PS, et al. The prevalence of anemia and iron de fi ciency is more common in breastfed infants than their mothers in Bhaktapur, Nepal. Nat Publ Group. 2015;70(4): 456-62. Available from: https://doi.org/10.1038/ejcn.2015.199.

33. Qasem W, Fenton T, Friel J. Age of introduction of first complementary feeding for infants: a systematic review. BMC Pediatr [internet]. BMC Pediatr. 2015. Available from: https://doi.org/10.1186/s12887-015-0409-5.

34. Mhanna RG, Rahal M, Iskandarani M, Hammoudi D. Incidence and risk factors associated with iron deficiency. Int J Pharm Pract. 2016;24:203-8.

35. Jordão ER, Bernardi JLD, de Azevedo Barros Filho A. Feeding pattern and anemia in infants in the city of Campinas, São Paulo, Brazil. Rev Paulista de Pediatr. 2009;27:381-8.

36. Luo R, Shi Y, Zhou H, Yue A, Zhang L, Sylvia S, et al. Anemia and Feeding Practices among Infants in Rural Shaanxi Province in China. Nutrients. 2014; 6:5975-91.

37. Ghana Landscape Analysis of Anemia and Anemia Programming. 2016; (April).

38. Ethiopian GTP2 Implementation Plan (2016-2030). 2016;(March).

Ready to submit your research? Choose BMC and benefit from:

- fast, convenient online submission

- thorough peer review by experienced researchers in your field

- rapid publication on acceptance

- support for research data, including large and complex data types

- gold Open Access which fosters wider collaboration and increased citations

- maximum visibility for your research: over $100 \mathrm{M}$ website views per year

At BMC, research is always in progress.

Learn more biomedcentral.com/submissions 